\title{
Determination of Trace Levels of Lead in Water Samples by Graphite Furnace Atomic Absorption Spectrometry After Dispersive Liquid-liquid Microextraction Based on Solidification of Floating Organic Drop
}

\author{
Pei Liang *, Juan Yu, Enjian Yang, and Lili Peng \\ Key Laboratory of Pesticide \& Chemical Biology of Ministry of Education, \\ College of Chemistry, Central China Normal University, \\ Wuhan 430079, P. R. China
}

\section{INTRODUCTION}

Lead $(\mathrm{Pb})$ is one of the most toxic elements with an accumulative effect and environmental toxicity. Lead can affect almost all organs and systems in the human body, especially the nervous system (1). The bad effects include blood enzyme changes, hyperactivity, and neurological disorders (2). The U.S. Environmental Protection Agency (EPA) classified $\mathrm{Pb}$ as a Group $\mathrm{B} 2$ (probable) human carcinogen, and published a regulation to control $\mathrm{Pb}$ in drinking water which included an action level of $0.015 \mathrm{mg} \mathrm{L}^{-1}$ (3). The World Health Organization (WHO) has released the guidelines for drinking water quality containing the guideline value of $0.01 \mathrm{mg} \mathrm{L}^{-1}$ for $\mathrm{Pb}$ (4). Because $\mathrm{Pb}$ has a tendency to accumulate and has a low rate of clearance, the concentrations of $\mathrm{Pb}$ in public water supply wells have reached unacceptable levels in many parts of the world (5). The determination of $\mathrm{Pb}$ levels in water samples is an essential step in water quality monitoring.

The determination of trace $\mathrm{Pb}$ in aqueous samples is often difficult due to matrix effects and because the concentration of $\mathrm{Pb}$ is lower than the detection limit of some instrumental methods. In order to achieve accurate and reliable analytical results, an efficient sample pretreatment procedure is often required. The most widely used techniques for the separation and preconcentration of trace $\mathrm{Pb}$

* Corresponding author.

E-mail: liangpei@mail.ccnu.edu.cn

\section{ABSTRACT}

A novel and environmentally friendly method has been developed for the determination of lead $(\mathrm{Pb})$ by dispersive liquidliquid microextraction based on solidification of floating organic drop (DLLME-SFOD) combined with graphite furnace atomic absorption spectrometry (GFAAS). In this method, 1-undecanol, which is of low density, low toxicity and has a proper melting point near room temperature, was used as the extraction solvent instead of a highly toxic organic solvent, and the phase separation was enhanced by solidification of the floating organic phase. Some parameters influencing the DLLME-SFOD extraction efficiency of $\mathrm{Pb}$ and its subsequent determination, such as type and volume of extraction and dispersive solvent, $\mathrm{pH}$ of sample solution, concentration of the chelating agent, extraction time and coexisting ions, were systematically investigated. Under the optimized conditions, the calibration graph exhibited good linearity over the $\mathrm{Pb}$ concentration range of $0.05-20.0 \mathrm{ng} \mathrm{mL}^{-1}$ with a correlation coefficient ( $r$ ) of 0.9975 . The detection limit of this method for $\mathrm{Pb}$ was $18 \mathrm{ng} \mathrm{L}^{-1}$ with an enhancement factor of 77 , and the relative standard deviation (RSD) was $3.8 \%$ at the $1.0 \mathrm{ng} \mathrm{mL}^{-1}$ $\mathrm{Pb}$ level. The method was successfully applied to the determination of trace amounts of $\mathrm{Pb}$ in water samples. include co-precipitation (6), liquidliquid extraction (LLE) (7), solidphase extraction (SPE) $(8,9)$, cloud point extraction (CPE) $(10,11)$, and liquid-phase microextraction (LPME) (12-15). Application of the conventional LLE and SPE methods is limited with the disadvantages such as being time-consuming, labor-intensive, and requiring large amounts of organic solvents. The LPME technique effectively overcomes these problems by reducing the amount of organic solvent and combining extraction, preconcentration, and sample introduction in one step.

Dispersive liquid-liquid microextraction (DLLME) and solidified floating organic drop microextraction (SFODME) are two relatively new modes of the LPME method. DLLME is based on the formation of fine droplets of the extraction solvent in the sample solution using a water-immiscible organic solvent (extraction solvent) dissolved in a water-miscible organic solvent (dispersive solvent). The advantages of this method are simplicity of operation, rapidity, low cost, and high enrichment factor (16). However, the majority of the extraction solvents used in the DLLME method are halogenated hydrocarbons which are environmentally hazardous and harmful to human health (17). For the SFODME method, the extraction solvents used are lighter than water and have melting points near room temperature. These solvents are not only less contaminating (considered as green extractants), but also easily collected due to its solidification at sub-ambient tempera- 
ture (18). This method is simple, accurate, low cost, and requires minimal organic solvent consumption, but the extraction rate is somewhat slower (19). In order to enjoy the advantages of the two techniques, a dispersive liquidliquid microextraction method based on solidification of floating organic drop (DLLME-SFOD) was introduced recently (20), and has been applied for the determination of trace organic pollutants and metal ions in environmental samples (21-24).

The aim of this work was to combine DLLME-SFOD with graphite furnace atomic absorption spectrometry (GFAAS) and develop a new method for the determination of trace $\mathrm{Pb}$ in water samples. In this method, dithizone was selected as the chelating reagent because it can form complexes with many metal ions and has found numerous applications in trace element separation and preconcentration $(25,26)$. The factors influencing the DLLME-SFOD extraction efficiency and GFAAS determination were systematically studied. The method was validated by analyzing a standard reference material and environmental water samples.

\section{EXPERIMENTAL}

\section{Instrumentation}

A TAS-990 atomic absorption spectrophotometer (Beijing Purkinje General Instrument Co. Ltd, Beijing, P.R. China), equipped with a deuterium background corrector and GF990 graphite furnace atomizer system, was used. $\mathrm{A} \mathrm{Pb}$ hollow cathode lamp was used as the radiation source at $283.3 \mathrm{~nm}$. The optimum operating parameters for GFAAS are given in Table I. All measurements were carried out in the integrated absorbance (peak area) mode. The $\mathrm{pH}$ values were measured with a Mettler Toledo 320-S pH meter (Mettler Toledo Instruments Co.. Ltd., Shanghai, P.R. China). A Model 0412-1 centrifuge (Shanghai Surgical Instrument Factory, Shanghai, P.R. China) was used to accelerate the phase separation.

\section{Standard Solution and Reagents}

A stock standard solution (1000 $\mu \mathrm{g} \mathrm{mL}^{-1}$ ) of $\mathrm{Pb}$ was obtained from the National Institute of Standards (Beijing, P.R. China). Working standard solutions were obtained by appropriate dilution of the stock standard solution. The solution of dithizone was prepared by dissolving an appropriate amount of dithizone (AR, Sinopharm Chemical

TABLE I

Operating Parameters for GFAAS

\begin{tabular}{|c|c|}
\hline \multicolumn{2}{|l|}{ Parameters } \\
\hline Lamp current & $2.0 \mathrm{~mA}$ \\
\hline Wavelength & $283.3 \mathrm{~nm}$ \\
\hline Slit & $0.4 \mathrm{~nm}$ \\
\hline Ar flow rate & $200 \mathrm{~mL} \mathrm{~min}^{-1}$ (stopped during atomizing) \\
\hline Sample volume & $20 \mu \mathrm{L}$ \\
\hline \multicolumn{2}{|c|}{ Temperature Program } \\
\hline Drying & $120^{\circ} \mathrm{C}(\operatorname{Ramp} 20 \mathrm{~s}$, Hold $10 \mathrm{~s})$ \\
\hline Ashing & $500^{\circ} \mathrm{C}($ Ramp $10 \mathrm{~s}$, Hold $10 \mathrm{~s})$ \\
\hline Atomizing & $1800^{\circ} \mathrm{C}($ Ramp 0 s, Hold $3 \mathrm{~s})$ \\
\hline Cleaning & $2100^{\circ} \mathrm{C}(\operatorname{Ramp} 1 \mathrm{~s}$, Hold $3 \mathrm{~s})$ \\
\hline
\end{tabular}

Reagent Company, Shanghai, P.R. China) in methanol. 1-undecanol, 1-dodecanol, and 2-dodecanol were obtained from Aladdin Reagent Company (Shanghai, P.R. China). A buffer solution of $0.1 \mathrm{~mol} \mathrm{~L}^{-1}$ NaAc-HAc was used to control the $\mathrm{pH}$ of the solutions. All other reagents used were of at least analytical reagent grade. Doubly distilled water was used throughout. Pipettes and vessels used in the experiments were kept in 10\% nitric acid for at least 24 hours and subsequently washed four times with doubly distilled water.

\section{DLLME-SFOD Procedure}

Aliquots of $5.0 \mathrm{~mL}$ sample solution containing $\mathrm{Pb}$ and $5.0 \times 10^{-5} \mathrm{~mol} \mathrm{~L}^{-1}$ dithizone were adjusted to $\mathrm{pH} 4.0$ with $0.1 \mathrm{~mol} \mathrm{~L}^{-1}$ NaAc-HAc buffer solution and placed in a $10 \mathrm{~mL}$ screw cap glass test tube with a conical bottom. The amount of $0.4 \mathrm{~mL}$ of methanol (dispersive solvent) containing $35 \mu \mathrm{L}$ of 1-undecanol (extraction solvent) was injected rapidly into the sample solution using a $1.00 \mathrm{~mL}$ syringe and manually shaken for 30 seconds. A cloudy solution was formed in the test tube, and the complex of $\mathrm{Pb}$ with dithizone was extracted into the fine droplets of 1-undecanol After centrifugation at $3000 \mathrm{rpm}$ for 5 minutes, the organic phase floated on the surface of the solution. The test tube was transferred into an ice bath, and the organic phase solidified after 5 minutes. The solidified solvent was then transferred into a conical vial where it melted immediately at room temperature (about $25 \mu \mathrm{L}$ ). A $20 \mu \mathrm{L}$ amount of the organic phase was injected into the GFAAS for analysis.

Calibration was performed against aqueous standards submitted to the same DLLME-SFOD procedure. A blank submitted to the same procedure described above was measured parallel to the sample and calibration solutions. 


\section{RESULTS AND DISCUSSION}

\section{Selection of Extraction Solvent and its Volume}

The extraction solvent used for DLLME-SFOD should have suitable physicochemical properties such as low volatility, low toxicity, lower density than water, and a melting point around room temperature (10-30 $\left.{ }^{\circ} \mathrm{C}\right)$. Hence, 1-undecanol (melting point $13-15^{\circ} \mathrm{C}$ ), 1-dodecanol $\left(22-24^{\circ} \mathrm{C}\right)$, and 2-dodecanol $\left(17-18^{\circ} \mathrm{C}\right)$ were investigated as the extraction solvent using $0.5 \mathrm{~mL}$ of methanol as the dispersive solvent; the results are shown in Figure 1. As can be seen, the highest absorbance signal of $\mathrm{Pb}$ was obtained using 1-undecanol as the extraction solvent. Therefore, 1-undecanol was selected as the extraction solvent for further studies.

In order to evaluate the effect of the extraction solvent volume on the extraction efficiency, $0.5 \mathrm{~mL}$ methanol containing different volumes of 1-undecanol $(35,40,45$, 50,55 , and $60 \mu \mathrm{L}$ ) were submitted to the same DLLME-SFOD procedure. It was found that the absorbance signal of $\mathrm{Pb}$ decreased as the volume of 1-undecanol increased because the volume of the organic phase increased from 25 to $45 \mu \mathrm{L}$. Thus, $35 \mu \mathrm{L}$ of 1 -undecanol was used as the extraction solvent in the subsequent experiments.

\section{Selection of Dispersive Solvent and its Volume}

For the DLLME method, the dispersive solvent should be miscible with both water and the extraction solvent, and form a stable twophase system in the presence of the extraction solvent when injected into an aqueous solution. Based on these considerations, methanol, acetonitrile, and acetone were tested as the dispersive solvent in this study, and the results are shown in Figure 2. It can be seen that the highest absorbance signal of $\mathrm{Pb}$ was obtained by using methanol as the dispersive solvent and was therefore chosen for the following experiments.

To obtain the optimized volume of the dispersive solvent, various experiments were performed using different volumes of methanol $(0.20 \sim 0.80 \mathrm{~mL})$ containing $35 \mu \mathrm{L}$ 1-undecanol. The results showed that the absorbance signal of $\mathrm{Pb}$ increased with an increase in the volume of methanol to $0.40 \mathrm{~mL}$. Reduction in the absorbance signal was observed after the volume of methanol exceeded $0.40 \mathrm{~mL}$ and was chosen as the optimum volume for further experiments.

\section{Effect of pH of the Sample Solution}

The $\mathrm{pH}$ of the sample solution plays an important role in the formation of the metal complex and the subsequent extraction. The effect of $\mathrm{pH}$ on the DLLME-SFOD extraction of $\mathrm{Pb}$ was studied over the $\mathrm{pH}$ range from 2 to 8 while keeping the other parameters constant. As can be seen in Figure 3, the highest absorbance signal of $\mathrm{Pb}$ was obtained at $\mathrm{pH}$ 4.0. Accordingly, $\mathrm{pH} 4.0$ was selected for subsequent work and the real water samples analysis.

\section{Effect of Dithizone Concentration}

Influence of the dithizone concentration on the extraction of $\mathrm{Pb}$ was evaluated in the concentration range of $1.0 \times 10^{-5} \mathrm{~mol} \mathrm{~L}^{-1}$ to $2.0 \times 10^{-4} \mathrm{~mol} \mathrm{~L}^{-1}$. The results showed that the absorbance signal of $\mathrm{Pb}$ increased with an increase in dithizone concentration up to $3.0 \times 10^{-5} \mathrm{~mol} \mathrm{~L}^{-1}$, and then remained nearly constant. In this study,

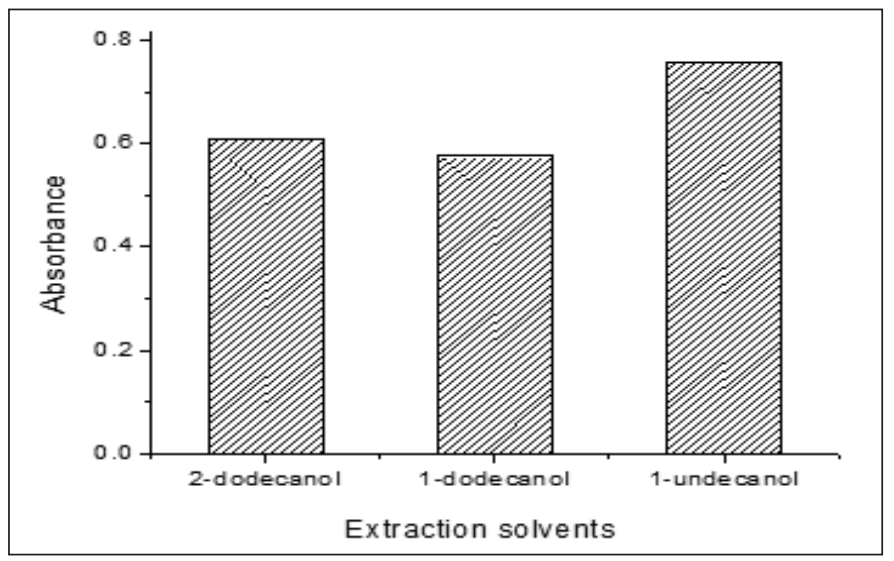

Fig. 1. Effect of different extraction solvents on the DLLME-SFOD extraction of $P b$.

DLLME conditions: $\mathrm{Pb}, 1.0 \mathrm{ng} \mathrm{mL}^{-1}$; sample volume, $5.0 \mathrm{~mL}$; pH of sample solution, 4.O; dispersive solvent (methanol) volume, $0.5 \mathrm{~mL}$; extraction solvent volume, $35 \mu \mathrm{L}$; dithizone concentration, $5.0 \times 10^{-5} \mathrm{~mol} \mathrm{~L}^{-1}$.

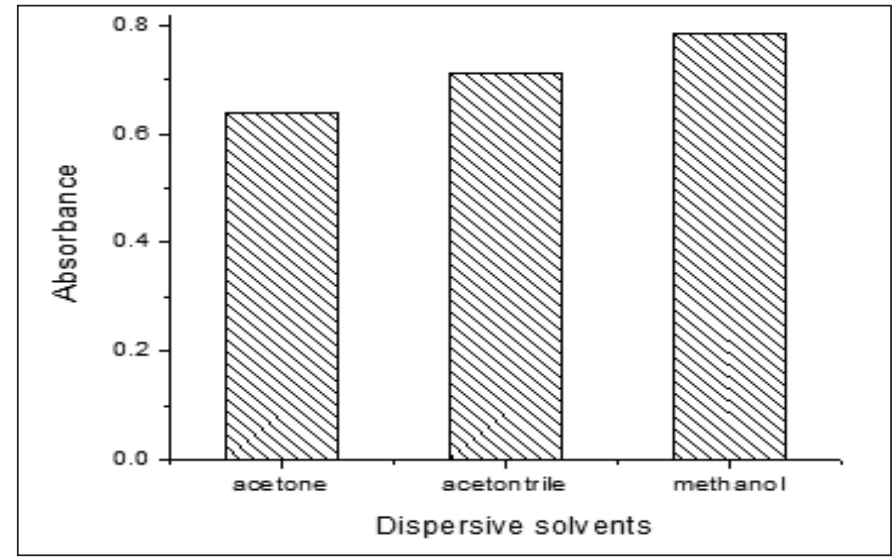

Fig. 2. Effect of different dispersive solvents on the DLLME-SFOD extraction of $P b$.

DLLME conditions: $\mathrm{Pb}, 1.0 \mathrm{ng} \mathrm{mL}^{-1}$; sample volume, $5.0 \mathrm{~mL}$; pH of sample solution, 4.0; dispersive solvent volume, $0.5 \mathrm{~mL}$; extraction solvent (1-undecanol) volume, 3; dithizone concentration, $5.0 \times 10^{-5} \mathrm{~mol} \mathrm{~L}^{-1}$ 
a dithizone concentration of $5.0 \times 10^{-5} \mathrm{~mol} \mathrm{~L}^{-1}$ was used to establish the presence of other extractable species in water samples that potentially interfere with the assaying of $\mathrm{Pb}$.

\section{Effect of Extraction Time}

The extraction time is defined as the interval time between the injection of the mixture of dispersive and extraction solvent and before the start of centrifugation. The effect of extraction time was examined in the range of 30 seconds to 10 minutes with the constant/ optimized experimental conditions. The obtained results showed that the extraction time has no significant influence on the absorbance signal of $\mathrm{Pb}$. The extraction of $\mathrm{Pb}$ was fast and time-independent because of the large surface area between the fine drops of the extraction solvent and the aqueous phase.

\section{Pyrolysis and Atomization Curves}

In order to avoid loss of $\mathrm{Pb}$ during the pyrolysis step and to obtain the highest absorbance signal, the optimum pyrolysis and atomization temperatures should be selected.
Pyrolysis and atomization curves were established using $1.0 \mathrm{ng} \mathrm{mL}^{-1}$ $\mathrm{Pb}$ solution submitted to the DLLME-SFOD procedure and are shown in Figure 4. From these curves, $500^{\circ} \mathrm{C}$ and $1800{ }^{\circ} \mathrm{C}$ were selected as the optimum pyrolysis and atomization temperatures, respectively. No matrix modifier was used because the considerable analyte stabilization was provided by the extraction medium itself.

\section{Effect of Coexisting Ions}

The potential interference in the present method was due to the competition of other metal ions for the chelating agent and their subsequent co-extraction with $\mathrm{Pb}$. The effect of coexisting ions on the extraction of $\mathrm{Pb}$ was investigated by submitting solutions containing $1.0 \mathrm{ng} \mathrm{mL}^{-1}$ of $\mathrm{Pb}$ and different amounts of the coexisting ion to the recommended procedure. The tolerance limits of the coexisting ions, defined as the largest amount making the recovery of $\mathrm{Pb}$ less than 90\%, are listed in Table II. As can be seen, the main ions in the water samples have no influence on the extraction of $\mathrm{Pb}$.

\section{Evaluation of Method Performance}

For the purpose of quantitative analysis, a calibration curve for $\mathrm{Pb}$ with concentrations ranging over four orders was obtained by spiking the standards directly into distilled water and extracting under the optimum conditions. Linearity was observed over the range of $0.05-20 \mathrm{ng} \mathrm{mL}^{-1}$ with a correlation coefficient $\left(\mathrm{R}^{2}\right)$ of 0.9975 . The limit of detection (LOD), based on a signal-to-noise ratio (S/N) of 3, was $18 \mathrm{ng} \mathrm{L}^{-1}$. The precision of this method was evaluated by analyzing the standard solution of $\mathrm{Pb}$ at the

TABLE II

Tolerance Limits of Coexisting Ions

\begin{tabular}{lc}
\hline $\begin{array}{l}\text { Coexisting } \\
\text { Ions }\end{array}$ & $\begin{array}{c}\text { Tolerance } \\
\text { Limits } \\
\left(\mathrm{mg} \mathrm{L}^{-1}\right)\end{array}$ \\
\hline $\mathrm{K}^{+}, \mathrm{Na}^{+}$ & 5000 \\
$\mathrm{Ca}^{2+}, \mathrm{Mg}^{2+}$ & 2000 \\
$\mathrm{Co}^{2+}, \mathrm{Zn}^{2+}, \mathrm{Cd}^{2+}, \mathrm{Ni}^{2+}$ & 250 \\
$\mathrm{Cu}^{2+}, \mathrm{Ag}^{+}$ & 10 \\
$\mathrm{Al}^{3+}, \mathrm{Cr}^{3+}, \mathrm{Fe}^{3+}$ & 5 \\
$\mathrm{NO}_{3}{ }^{-}, \mathrm{Cl}^{-}$ & 5000 \\
$\mathrm{SO}_{4}{ }^{2-}$ & 2500 \\
\hline
\end{tabular}

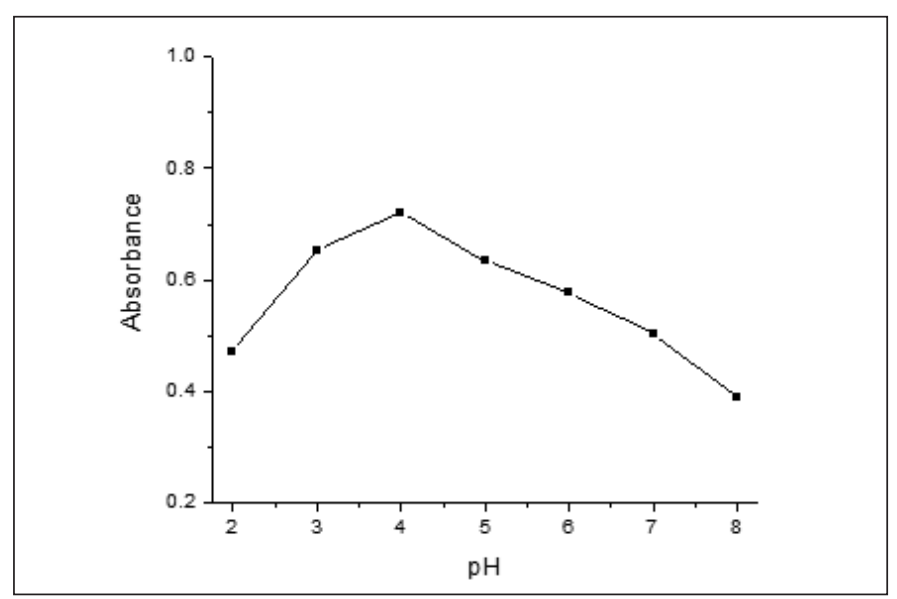

Fig. 3. Effect of $p H$ of the sample solution on the DLLME-SFOD extraction of $\mathrm{Pb}$.

DLLME conditions: $\mathrm{Pb}, 1.0 \mathrm{ng} \mathrm{mL}^{-1}$; sample volume, $5.0 \mathrm{~mL}$; dispersive solvent (methanol) volume, $0.4 \mathrm{~mL}$; extraction solvent (1-undecanol) volume, $35 \mu \mathrm{L}$; dithizone concentration, $5.0 \times 10^{-5} \mathrm{~mol} \mathrm{~L}^{-1}$.

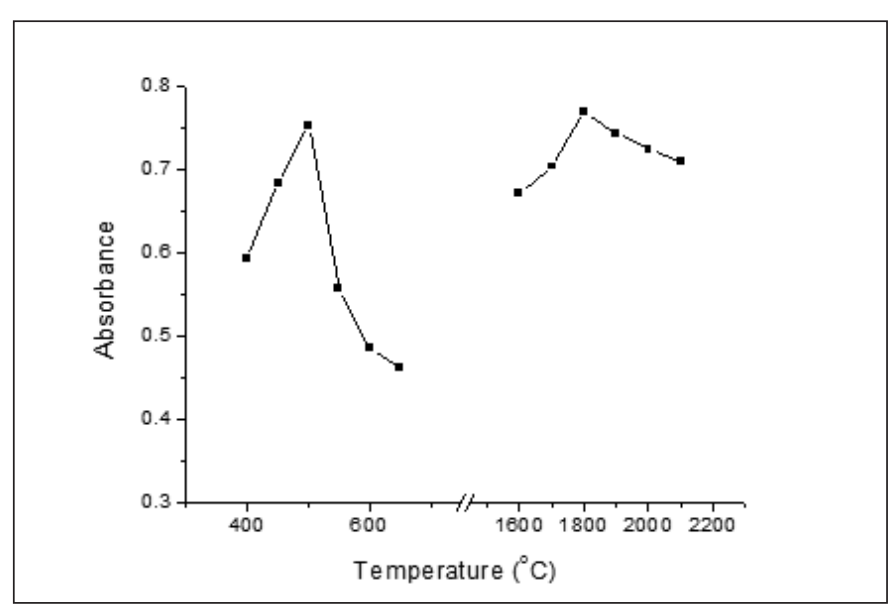

Fig. 4. Pyrolysis curve (a) and atomization curve (b) for $\mathrm{Pb}$. DLLME conditions: $\mathrm{Pb}, 1.0 \mathrm{ng} \mathrm{mL}^{-1}$; sample volume, $5.0 \mathrm{~mL}$; pH of sample solution, 4.O; dispersive solvent (methanol) volume, $0.4 \mathrm{~mL}$; extraction solvent (1-undecanol) volume, $35 \mu \mathrm{L}$; ditbizone concentration, $5.0 \times 10^{-5} \mathrm{~mol} \mathrm{~L}^{-1}$. 
$1.0 \mathrm{ng} \mathrm{mL}{ }^{-1}$ level seven times in succession, and the relative standard deviation (RSD) was 3.8\%. The enhancement factor calculated as the slope ratio of the calibration curves, obtained with and without extraction, was 77 for $5.0 \mathrm{~mL}$ sample solutions.

\section{Real Sample Analysis}

In order to establish the validity of the proposed procedure, the method has been applied to the determination of $\mathrm{Pb}$ in an environmental water reference material (GSBZ50009-88). The analytical value $\left(1.05 \pm 0.03 \mu \mathrm{g} \mathrm{mL}^{-1}, \mathrm{n}=3\right)$ is in good agreement with the certified value $\left(1.02 \pm 0.04 \mu \mathrm{g} \mathrm{mL}^{-1}\right)$.

The proposed method has also been applied to the determination of $\mathrm{Pb}$ in lake water and tap water samples. Lake water samples were collected from East Lake (Wuhan, P.R. China), and tap water samples were freshly collected in our laboratory after allowing the water to flow for 5 minutes. All water samples were filtered through a $0.45 \mu \mathrm{m}$ membrane filter and analyzed as quickly as possible after sampling. In addition, the recovery experiments of different amounts of $\mathrm{Pb}$ were carried out, and the results are listed in Table III. As can be seen, the results indicate that

TABLE III

Determination of $\mathbf{P b}$ in Water Samples

Samples Added Found ${ }^{\mathrm{a}}$ Recovery

\begin{tabular}{lccr} 
& $\left(\mathrm{ng} \mathrm{mL}^{-1}\right)$ & $(\%)$ \\
\hline Lake & & & \\
Water & 0 & $2.9 \pm 0.3$ & - \\
& 5 & $8.0 \pm 0.6$ & 102 \\
& 10 & $12.6 \pm 0.8$ & 97
\end{tabular}

Tap

$\begin{array}{cccc}\text { Water } & 0 & 1.4 \pm 0.2 & - \\ & 5 & 6.2 \pm 0.5 & 96 \\ & 10 & 10.9 \pm 0.7 & 95\end{array}$

${ }^{a}$ mean \pm S.D., $n=5$. the recoveries in the range of $95-102 \%$ are reasonably well for trace analysis.

\section{CONCLUSION}

The results obtained in this work demonstrate that the developed DLLME-SFOD preconcentration method with GFAAS analysis is a simple, rapid, and sensitive method for the determination of trace $\mathrm{Pb}$ in water samples. Using 1-undecanol with lower toxicity instead of toxic organic solvents as the extraction solvent is an excellent benefit of the proposed method and makes the method a green and environmentally friendly analytical technique that can be applied for routine analysis.

$\overline{\text { Received October 7, } 2013 .}$

\section{REFERENCES}

1. H.R. Pohl, H.G. Abadin and J.F. Risher, Neurodegenerative Diseases and Metal Ions: Metal Ions in Life Sciences, Vol. 1, Wiley, Chichester, UK, pp. 397-408 (2006).

2. G. Nordberg, Handbook on the Toxicology of Metals, Academic Press, New York (2007).

3. United States Environmental Protection Agency, Lead and Copper Rule (LCR) 56 FR (1991).

4. World Health Organization, Guidelines for Drinking-Water Quality: First Addendum to Third Edition, Vol. 1, 2006 recommendation.

5. W. Jung, A. Jang, P.L. Bishop and C.H. Ahn, Sens. Actuators B 155,145 (2011).

6. S. Saracoglu, M. Soylak, D.S.K. Peker, L. Elci, W.N.L. dos Santos, V.A. Lemos and S.L.C. Ferreira, Anal. Chim. Acta 575, 133 (2006).

7. J.H. Wang and E.H. Hansen, J. Anal. At. Spectrom. 17, 1284 (2002).

8. Y.K. Wang, S.T. Gao, X.H. Zang, J.C. Li and J.J. Ma, Anal. Chim. Acta 716, 112 (2012).
9. H.M. Jiang, Z.P. Yan, Y. Zhao, X. Hu and H.Z. Lian, Talanta 94, 251 (2012).

10. F. Shah, T.G. Kazi, H.I. Afridi, Naeemullah, M.B. Arain and J.A. Baig, J. Hazard. Mater. 192, 1132 (2011).

11. C.Y. Zhang, Y.N. Wang, X.R. Cheng, H.B. Xia and P. Liang, Atom. Spectrosc. 32, 189 (2011).

12. P. Liang and H.B. Sang, Anal. Biochem. 380, 21 (2008).

13. J. Cao, P. Liang and R. Liu, J. Hazard. Mater. 152, 910 (2008).

14. J.L. Manzoori, M. Amjadi and J. Abulhassani, Anal. Chim. Acta 644, 48 (2009).

15. F. Shah, M. Soylak, T.G. Kazi and H.I. Afridi, J. Anal. Atom. Spectrom. 27, 1960 (2012).

16. H.Y. Yan and H. Wang, J. Chromatogr. A 1295, 1 (2013).

17. Y.Y. Wang, G.Y. Zhao, Q.Y. Chang, X.H. Zang, C. Wang and Z. Wang, Chinese J. Anal. Chem. 38, 1517 (2010).

18. M. Ghambarian, Y. Yamini and A. Esrafili, Microchim. Acta 180, 519 (2013).

19. J.F. Xiong, Z. Guan, G.M. Zhou, X.Y. Tang, Y.J. Lv and H.L. Wang, Anal. Methods 4, 3246 (2012).

20. M.I. Leong and S.D. Huang, J. Chromatogr. A 1211, 8 (2008).

21. D. Afzali, A.R. Mohadesi, B.B. Jahromi and M. Falahnejad, Anal. Chim. Acta 684, 54 (2011).

22. C.P. Diao and C.H. Wei, Anal. Bioanal. Chem . 403, 877 (2012).

23. N.B. Lana, P. Berton, A. Covaci, A.G. Atencio, N.F. Ciocco and J.C. Altamirano, J. Chromatogr. A 1285 , 15 (2013).

24. M.D.M. Abadi, M. Chamsaz, M.H. Arbab-Zavar and F. Shemirani, Anal. Methods 5, 2971 (2013).

25. M.E. Mahmoud, M.M. Osman, O.F. Hafez, A.H. Hegazi and E. Elmelegy, Desalination 251, 123 (2010).

26. H.M. Yu, H. Song and M.L. Chen, Talanta 85, 625 (2011). 